Buch, wie das vorliegende, meht jede neue kirscheinung der litteratur aufnehmen, sondern muß den Bestand zu wahren suchen und eine Klärung der Ansichten abwarten.

In der ganzen Anlage ist das Buch dasselbe geblieben.

Auch diesmal bin ich durch spontane Äußerungen aus dem Krreise der Interessenten unterstützt worden; allen Gönnern des Buches meinen verbindlichsten Dank.

Heidelberg, Winter 1886.

\title{
J. Steiner.
}

\section{Vorwort zur funften Auflage.}

Der vorläufige AbschluB, welchen die Lehre von der Sekretion und Resorption durch die . Irbeiten der letzten Jahre erhalten hat, ist auch bei der neuen Darstellung zum Ausdruck gekommen, insofern noch nachdrücklicher als früher die aktive Leistung der Zelle herrorgehoben werden konnte. Nicht minder muBten auf Grund neuerer Arbeiten Verbesserungen in fast allen Tellen des Buches angebracht werden, ohne indes den bisherigen Umfang im wesentlichen zu überschreiten.

Wenn es also eine durchaus verbesserte Auflage ist, so tritt sie dem Publikum doch in der alten Fassung entgegen; sie hofft auch diesmal eine günstige Aufnahme und eine wohlwollende Beurteilung zu finden.

Köln, im Januar 1890.

\section{J. Steiner.}

